\title{
STRUCTURAL ANALYSIS OF TURKISH AIRSPACE BY USING GIS
}

\author{
Kadriye Yaman ${ }^{1}$ \\ Faculty of Aeronautics and Astronautics, Anadolu University, Eskisehir, Turkey \\ Hakan Oktal ${ }^{2}$ \\ Faculty of Aeronautics and Astronautics, Anadolu University, Eskisehir, Turkey \\ Metin Altan ${ }^{3}$ \\ Faculty of Science, Anadolu University, Eskisehir, Turkey
}

\begin{abstract}
In parallel with the rapid growth in Turkish air transportation, air traffic density and congestion of Turkish airspace have been increasing in recent years. The aim of this study is to examine the structural features and the capacity of Turkish airspace. In this context, the map of Turkish airspace containing sector boundaries, routes and waypoints is digitized and transferred to the GIS environment. The real traffic data of Turkish airspace for a period of two peak hours in heavy traffic during August 2007 was provided by the General Directorate of Turkish Airports. Analysis results indicate that the traffic density of Turkish airspace is accumulative especially in certain sectors. The results obtained from the analyses were compared with the existing sector structure of Turkish airspace and some suggestions related to capacity problems are provided. These suggestions can also be used for the strategic planning of airspace.
\end{abstract}

Keywords: Airspace Management, Air Traffic Control, Geographical Information Systems

\footnotetext{
${ }^{1}$ Kadriye Yaman is an Assistant Professor in the Faculty of Aeronautics and Astronautics, Anadolu University, Turkey. She received her MSc Degree from Anadolu University in Turkey in 2002 and a PhD Degree in Civil Aviation from the Anadolu University in Turkey in 2010. Her research areas are air navigation systems, air traffic management and air laws. Email address: kyaman@anadolu.edu.tr (Corresponding Author)

${ }^{2}$ Hakan Oktal is an Associate Professor in the Faculty of Aeronautics and Astronautics, Anadolu University, Turkey. He obtained his MSc Degree from the Ecole Nationale de I'Aviation Civile (ENAC) in France in 1990 and a PhD Degree in Civil Aviation from the Anadolu University in Turkey in 1998. His current research interests include airport planning and design, air navigation systems and air traffic management. Email address: hoktal@anadolu.edu.tr
}

${ }^{3}$ Metin Altan is an Assistant Professor in Faculty of Science, Anadolu University, Turkey. He received his doctorate degree in Physics from Anadolu University in 2002. His current research interests include Remote Sensing, Geographic Information Systems, 3D Locational Modelling and Digital Mapping with Interactive Data Base. Email address: maltan@anadolu.edu.tr 


\section{INTRODUCTION}

Effective management of airspace is an important and difficult problem. In many en-route regions, air traffic is expected to exceed current capacity limits, i.e. the maximum number of aircraft allowed in a given airspace, as defined by controllers. An overestimated capacity may lead to congestion delays or safety breaches with respect to minimum aircraft separation (Salaün, 2009). Rapid growth in air traffic volume steadily increases complexity and produces drawbacks such as: system bottlenecks, indirect routing, and lack of navigation freedom for airlines (Hand et al., 2011). Galster et al. (2001) argue that controllers had difficulty both in detecting conflicts and in recognizing self-separating events in saturated airspace according to performance and workload measurements. A number of factors affect controller workload; these factors include, but are not limited to, potential conflicts, number of handoffs, heading and speed differences, aircraft proximity to each other, sector boundaries, presence of severe weather, and traffic density (Kopardekar et al., 2009).

Maximizing the efficiency of the airspace system and providing a smooth and safe flow of traffic are the main objectives of Air Traffic Management (ATM). Effective airspace organization and management enhance the ability of the ATM service provider and airspace users and also increase ATM system safety, capacity and efficiency (ICAO, 2005). Therefore strategic and tactical planning of airspace is an important function to enable flight punctuality and efficiency by optimizing the network capacity through collaborative decision making process. The strategic planning for airspace management requires a long-term focus in order to produce a coordinated plan of demand and capacity for up to 18 months ahead. It consists of analyzing the evolution of the forecast demand and the identification of potential new problems and the evaluating possible solutions. The outputs of this process are the capacity and route allocation plans for the following year. The strategic planning of airspace is aimed at forecasting the need for capacity and at adjusting the demand in order to prevent strong imbalances with the available capacity (Eurocontrol, 2004).

The main purpose of this study is to explore the potential capacity problems of Turkish airspace and to propose some solutions which can be taken into account in the strategic planning process. In this study, Geographical Information Systems (GIS) are used as a tool for the measurement of controller workload in each sector, the monitoring of traffic distribution on waypoints, attaining its characteristics and also the analyzing all kinds of data. Escobar et al. (2005) indicate that GIS is considered as an important tool in planning and 
decision-making. GIS can also generate recommendations and solutions for the strategic planning of airspace.

In this framework, 1:2000000 scale en-route map of Turkish airspace containing sector boundaries, routes and waypoints is digitized and converted to the appropriate format with geographic coordinate assignment and then transferred to GIS environment. The real traffic data of Turkish airspace for two peak hours period in heavy traffic covering August 2007 was provided by the General Directorate of Turkish Airports (DHMI). This data contains the call signs, types, takeoff and departure points of the aircraft, the location of the fix points, and arrival time and flight level of the aircraft on these fixes. The data table prepared in Excel format is transferred to GIS environment. Geomedia 6.1 Professional GIS software was employed for the visualization of the real traffic data.

The analyses performed in this study are given below:

- Description of the general characteristics of Turkish airspace;

- Determining the traffic density in waypoints;

- Detection of the potential conflicts between aircraft; and

- Evaluation of sector densities according to the number of aircraft.

\section{ANALYSING TURKISH AIRSPACE}

\subsection{The Structure of Turkish Airspace}

Turkey has a strategically important airspace with approximately 61 thousand kilometers of controlled air routes and one million square kilometers of controlled airspace over Europe and Asia continents. Due to its special geographical location, Turkish airspace includes crossroads with north-south and east-west traffic flows between Europe, Asia and the Middle East (DHMI, 2011). According to the DHMI statistics, annual aircraft traffic in Turkish Airspace increased more than twice between the years 2003 and 2013. This result shows that the growth rate of aircraft traffic in Turkey exceeds the average for other European countries.

In this study, air routes, boundaries of 6 sectors and 312 waypoints of which 64 are radio navigation aids, 100 reporting points and 148 fix are defined with their geographical coordinates into GIS environment. It is also determined that 296 aircraft fly in Turkish airspace in two peak hours. The data related to flight trajectories of 296 aircraft are prepared in Excel format. The flight data table which contains aircraft type and call sign, 
departure and destination points, air route and waypoint names, and flight level and time over each waypoint is loaded to the GIS for airspace analyses.

Figure 1 illustrates the waypoint locations and air routes of Turkish airspace. As depicted in this figure, it is possible to interrogate the features and the densities of any selected route (name, length, minimum flight level requested, number of aircraft flying on a route in two peak hours) and its traffic details (call sign, type, speed and flight level of aircraft). The routes witnessing relatively higher aircraft traffic (namely more than 10 aircraft in two hours) during peak periods are also designated in same figure with solid bold lines. As seen from this figure, the density of the traffic incoming from and outgoing to the north and the south directions is higher in the western part of Turkey. The speed of aircraft in accordance with the flight level was received from aircraft performance technical document - BADA (Nuic, 2004). The speeds for intermediate values of flight levels which did not feature in the document were calculated with interpolation method.

Figure 1: The location of Waypoints and Air routes in Turkish Airspace

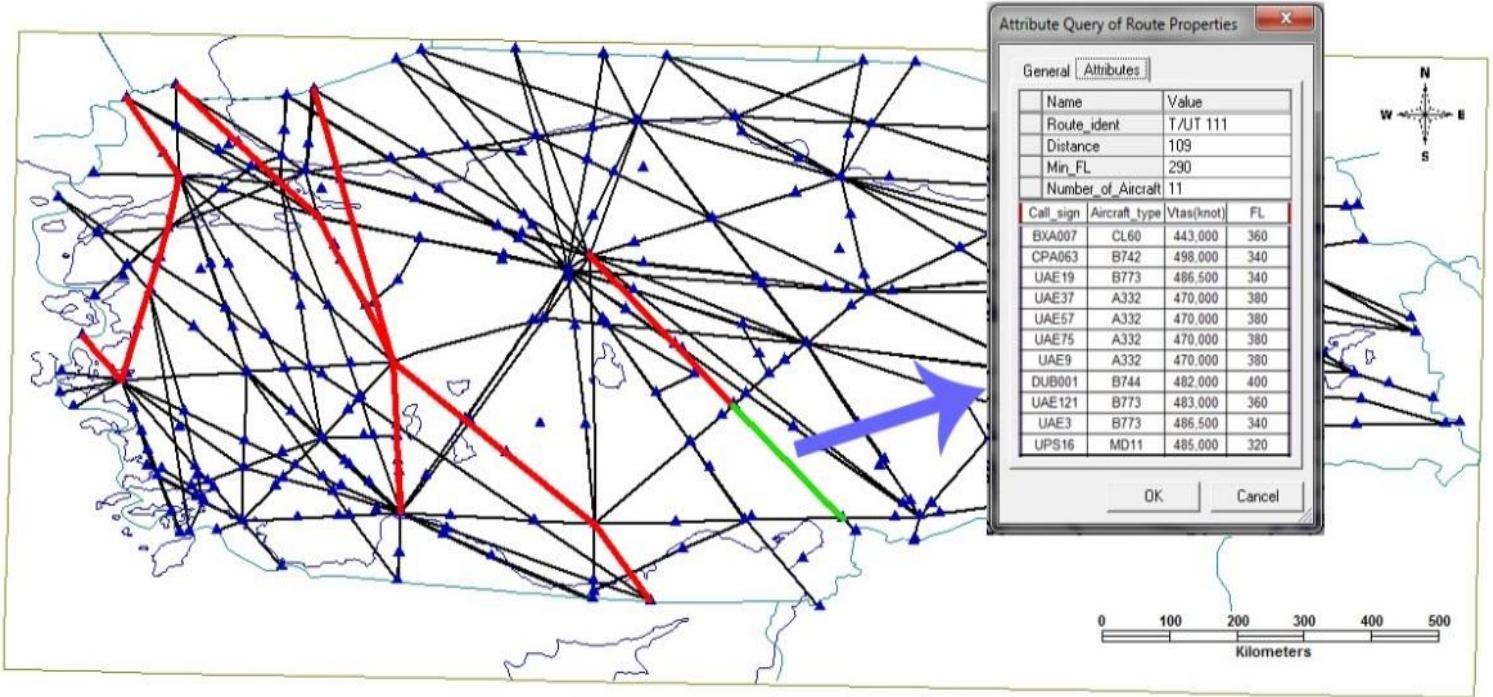

\subsection{Traffic Density in Waypoints}

The controller performance and workload vary as a function of traffic density. As seen in Figure 2, the highest traffic density in Turkish airspace appears on the waypoints situated in western part of Turkey. Each flight is represented by a buffer in order to visualize the traffic density on each waypoint. The buffer diameter increases proportionally according to the number of aircraft passing through the waypoint. The name, the coordinates and the traffic statistics of a waypoint can be displayed on the screen by clicking on it. It is also possible to 
investigate the flight details of each aircraft flying over a waypoint. The number of aircraft, mix of aircraft, separation between aircraft, closing rates, aircraft speeds and flow restrictions influence the controller workload. In the waypoints having high traffic density, the complexity of traffic and the controller's mental operations in higher workload can increase the risk of aircraft conflict.

Figure 2: Traffic Density of Turkish Airspace in Two Peak Hours

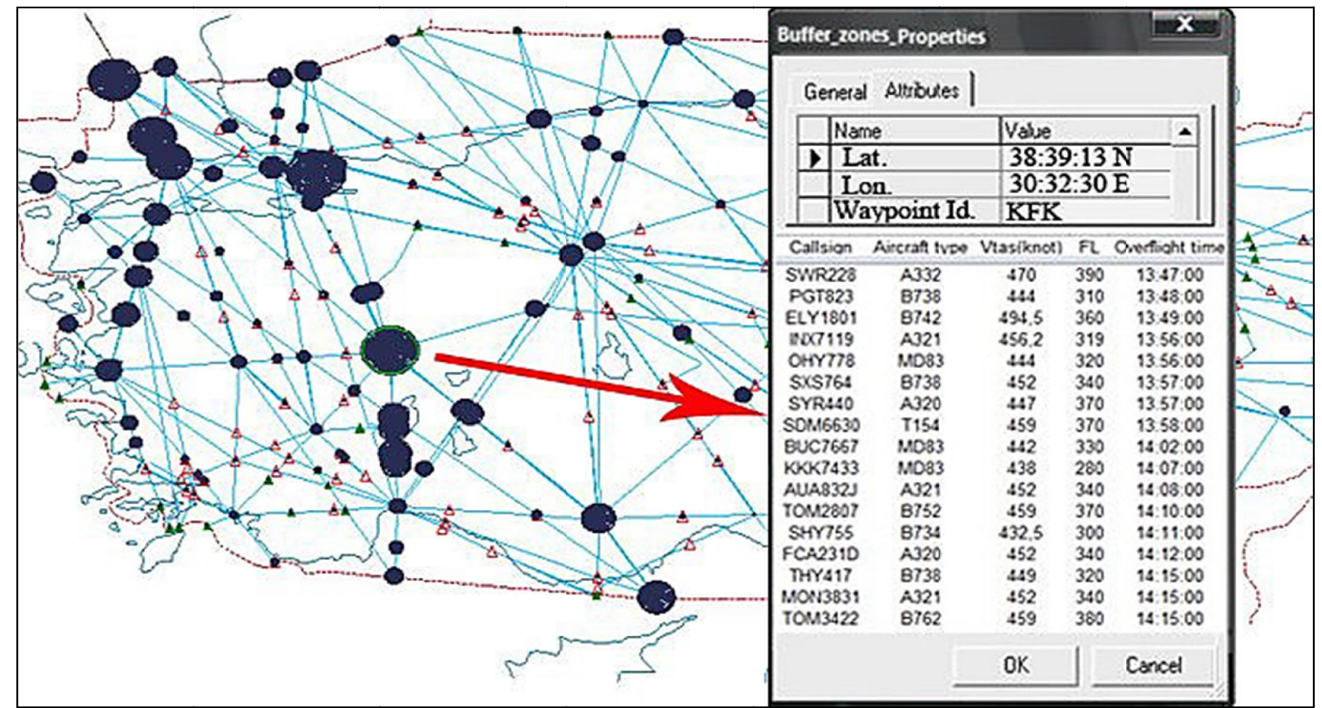

\subsection{Aircraft Conflicts}

Controller workload is the main factor limiting en-route airspace capacity. As Albasman and $\mathrm{Hu}$ (2010) mentioned in their study, conflict prediction and avoidance is a critical and challenging task in air traffic management systems. The airspace management activities such as demand and capacity balancing and traffic synchronization obviously have a close connection to conflict management (ICAO, 2005).

Hilburn (2004) states that traffic density is not only an important driver of complexity, but also correlates well with conflict rate. In this framework, the protected zone for the conflicts in en-route airspace in Turkey is currently defined by Aeronautical Information Publication (DHMI, 2012) as a horizontally 10 NM and vertically 1,000 ft. Lindberg and Värbrand (2001), state that 8 NM separation during cruise translates into one minute. In this study, approximately one minute horizontal and $1000 \mathrm{ft}$. vertical separations between aircraft are considered as potential conflict, and less than these separation values are taken into account as a conflict. 
Different types of conflict identified by ICAO (2007) are as follows:

- Conflicts between aircraft on the same track and level (C1)

- Conflicts between aircraft on crossing tracks at the same level (C2)

- Conflicts between climbing or descending aircraft on the same track (C3)

- Conflicts between climbing or descending aircraft on crossing tracks (C4)

- Conflicts between climbing or descending aircraft on reciprocal track (C5)

The detected conflicts and potential conflicts in Turkish airspace during two peak hours are given in Table 1. As seen from the table, conflict between aircraft on the same track and level is the most encountered conflict type in two peak hours. The flight trajectories of different aircraft can be visualized by GIS in order to monitor potential aircraft proximities.

Table 1: The Number of Conflicts and Potential Conflicts

\begin{tabular}{cccccccc}
\hline & \multicolumn{4}{c}{ Types of Conflict (Number of Event) } & & Total \\
\cline { 2 - 7 } & $\mathbf{C}_{\mathbf{1}}$ & $\mathbf{C}_{\mathbf{2}}$ & $\mathbf{C}_{\mathbf{3}}$ & $\mathbf{C}_{\mathbf{4}}$ & $\mathbf{C}_{\mathbf{5}}$ & \\
\hline Conflict & 4 & 1 & 1 & 0 & 1 & 7 \\
\hline Potential Conflict & 9 & 4 & 4 & 1 & 0 & 18 \\
\hline
\end{tabular}

\subsection{Traffic Density in Sectors}

Air traffic control is currently based on sector structures. The airspace is divided into many sectors whose size depends on the average traffic volume and the geometry of air routes (Nguyen-Duc et al., 2008). Sectorization is the means of subdividing the totality of control tasks into manageable portions, at which throughput and capacity can be quantified. The classic method to overcome airspace limitations and controller workload is to provide more sectors. By either resizing or providing additional sectors, the airspace volume, the number of routes/crossing points and the number of aircraft can be reduced. This results in a reduction of workload and a corresponding increase in capacity (Eurocontrol, 2002).

As seen in Figure 3, Turkish Airspace was composed of 6 sectors horizontally and 11 sectors vertically in 2007. Sector properties such as the number of aircraft within different flight levels, sector area and the total number of waypoints can be displayed by clicking on the corresponding sector in GIS environment. 
Figure 3: Sector Features of Ankara West

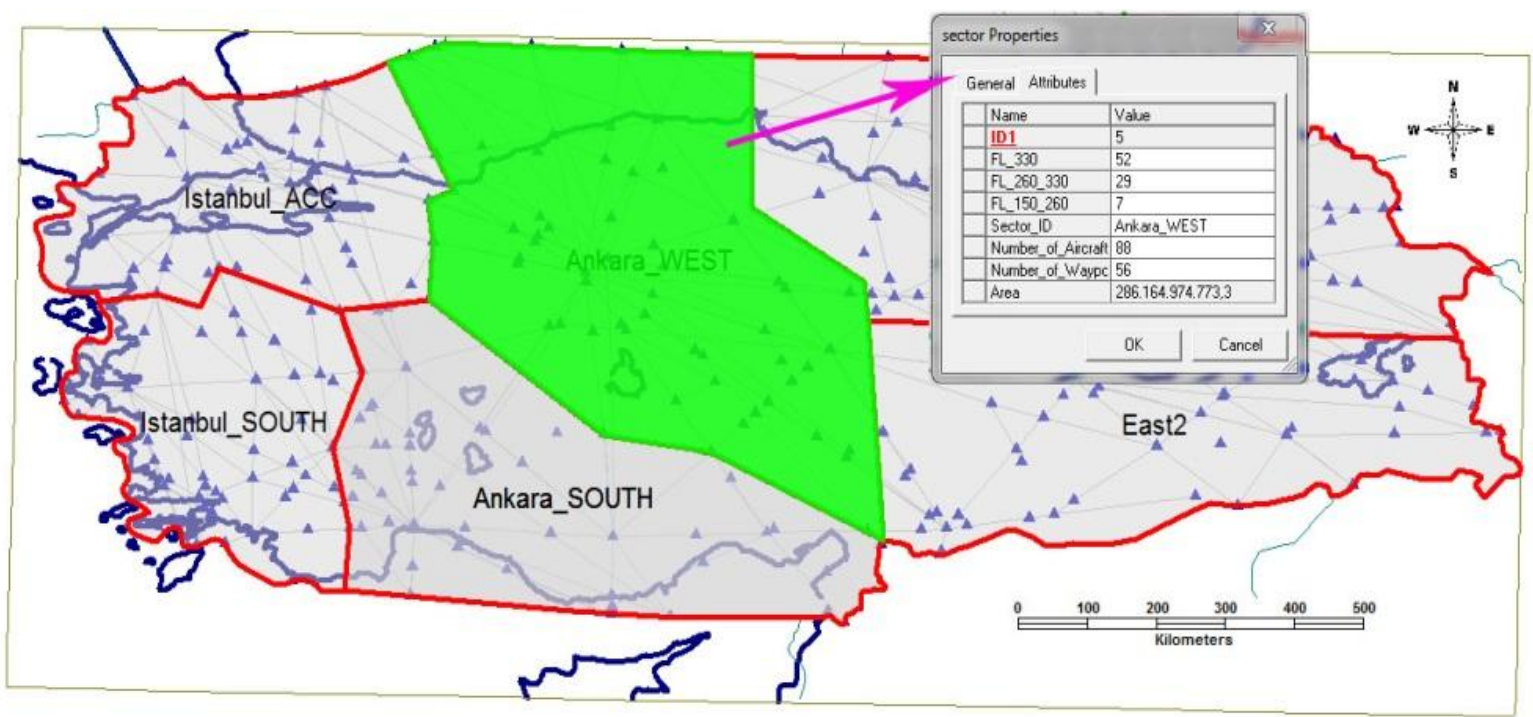

The number of aircraft and the number of traffic services provided according to the type of aircraft movement (such as heading change, speed change and flight level change) in each sector during one peak hour (26 August 2007, 14:00 to 15:00) are summarized in Table 2. As seen from the table, the sectors are also divided vertically to minimize controller workload by taking the sector densities into account. In this table, the following tasks are calculated in the same way as the study of Laudeman et al. (1998):

- Heading change: The number of aircraft that made a heading change greater than $15^{\circ}$.

- Speed change: The number of aircraft that had a computed air speed change greater than 10 knots.

- Flight level change: The number of aircraft that achieved an altitude change greater than $750 \mathrm{ft}$.

Eurocontrol (2010) argues that a controller can provide service for 40-60 aircraft per hour in heavy traffic. From this point of view, more than 40 aircraft in one hour per sector is assumed as "high traffic density". Whereas a density between 30 and 40 aircraft in one hour corresponds to "medium density" and finally less than 30 aircraft is accepted as "low density". Traffic densities of each sector are depicted in Figure 4. Ankara South and Istanbul ACC are the sectors which have high traffic densities in Turkish airspace. The results of the conflict analyses shows that 5 conflicts of 7 and 15 potential conflicts of 18 given in Table 2 
are detected in these sectors. This situation confirms directly proportional relationship between the traffic density and the risk of aircraft conflict.

Table 2: Sector Densities in One Peak Hour

\begin{tabular}{lcccc}
\hline Sectors & $\begin{array}{c}\text { Number of } \\
\text { Aircraft }\end{array}$ & $\begin{array}{c}\text { Number of } \\
\text { Heading } \\
\text { Change }\end{array}$ & $\begin{array}{c}\text { Number of } \\
\text { Speed } \\
\text { Change }\end{array}$ & $\begin{array}{c}\text { Number of } \\
\text { Flight Level } \\
\text { Change }\end{array}$ \\
\hline Istanbul_Upper & 68 & 27 & 11 & 24 \\
Istanbul_Intermediate & 42 & 27 & 20 & 31 \\
Istanbul_Lower & 59 & 52 & 132 & 143 \\
Istanbul_South_Upper & 32 & 5 & 7 & 19 \\
Istanbul_South_Lower & 38 & 32 & 93 & 100 \\
Ankara_West_Upper & 39 & 24 & 1 & 6 \\
Ankara_West_Lower & 27 & 18 & 21 & 28 \\
Ankara_South_Upper & 43 & 34 & 0 & 5 \\
Ankara_South_Lower & 42 & 22 & 72 & 91 \\
East_1 & 20 & 18 & 7 & 12 \\
East_2 & 20 & 23 & 15 & 22 \\
\hline
\end{tabular}

Figure 4: Traffic Densities of Sectors

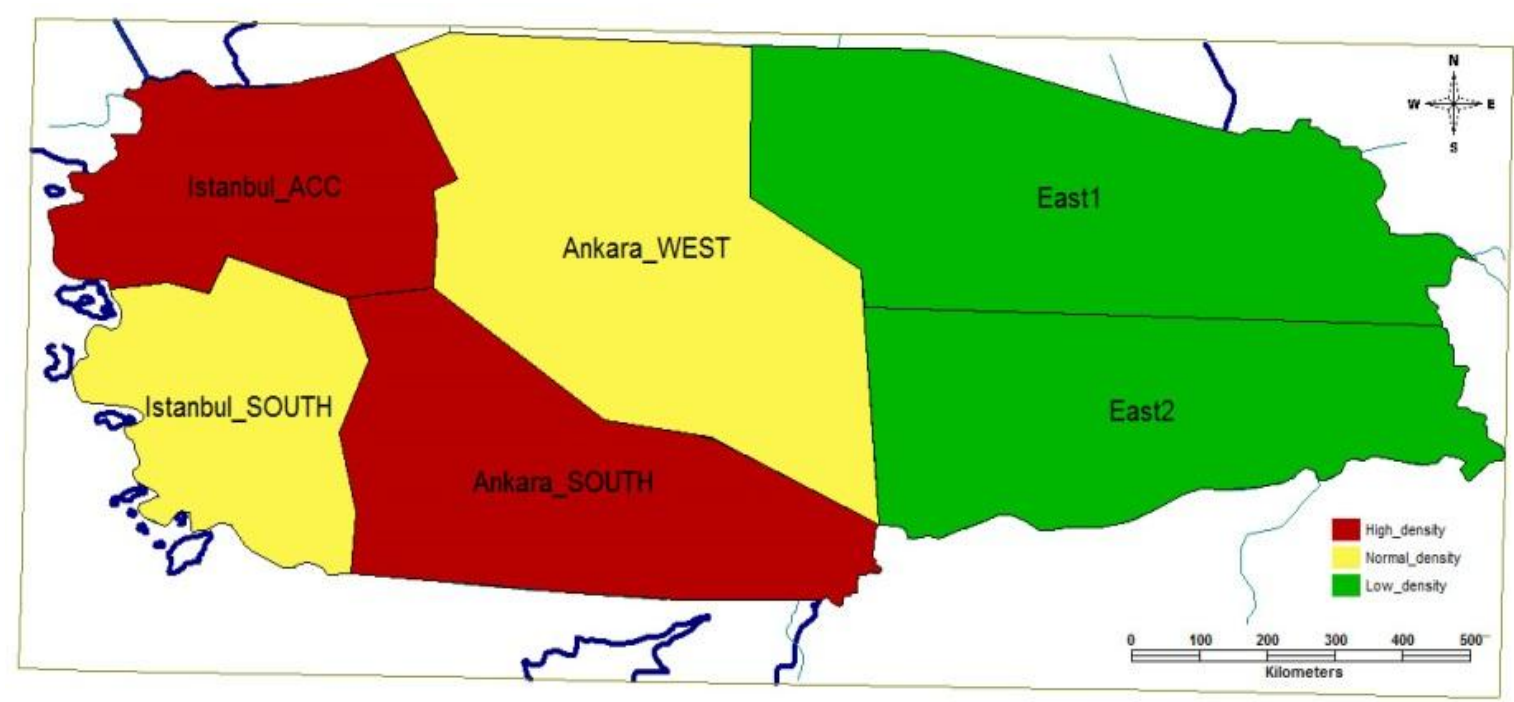

\section{ANALYSIS RESULTS}

From the results of the analysis, it is observed that the distribution of controller workload among sectors according to number of aircraft and types of aircraft movement is not balanced. According to the information received from the controllers working in Istanbul ACC, separations of aircraft coming from the upper or the lower sectors to intermediate level, causes the increase of the controller workload and airspace complexity in the intermediate sector. The allocation of related routes in single direction seems to be a solution of this problem. However, this solution proposed may decrease the traffic capacity 
of the sector. As such, this situation may require the restructuring of the horizontal and vertical sector boundaries of Turkish airspace.

According to the aircraft traffic statistics of DHMI between the years 2007 and 2013, it is found that the aircraft traffic in Turkish airspace growth approximately $60 \%$ in six years. Eurocontrol statistics released in 2012 indicate that Istanbul Ataturk-İzmir Adnan Menderes and İstanbul Ataturk-Antalya are the first and third busiest airport pairs respectively per number of daily flights in Europe. Assuming the sector structure of Turkish airspace does not change, it is seen that the sector capacities do not meet the existing and future demands. This inconvenience can be resolved by increasing the number of sectors, restructuring sector boundaries and by adding new routes to the existing airspace. Concordantly, the Turkish airspace was restructured in September 2010. The new sectors and the new routes were defined in the new airspace system. These sectors are especially opened in peak traffic periods. The new sector structure of Turkish airspace is illustrated in Figure 5.

Figure 5: The New Sector Structure of Turkish Airspace

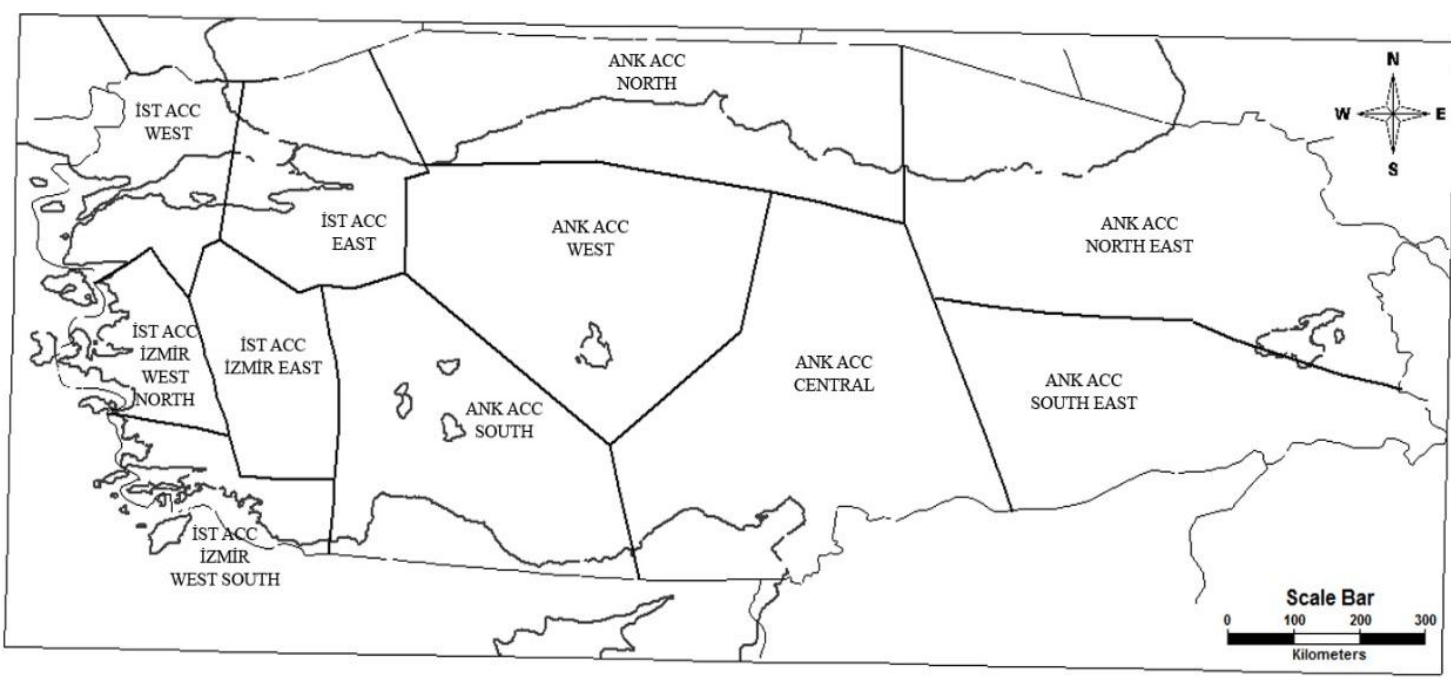

The features of old and new airspace structures are also compared in Table 3. In the new sector structure while the number of upper and lower sectors have been augmented, the intermediate sectors are eliminated to decrease aircraft collusion risk and the controller coordination workload. Eurocontrol (2002) argues that the sub-division of sectors is a finite strategy. Furthermore, the increase of capacity is not proportional to the number of sectors available. The provision of additional sectors is the classic method of increasing capacity. Although scope still exists for this in most of many airspace, this is not always the most efficient method. Additional sectors are not always possible because of frequency shortage, 
increase in coordination workload among sectors, short transit times and complex network for lower airspace.

Table 3: Comparing Old and New Structures of Turkish Airspace

\begin{tabular}{cccc}
\hline \multirow{2}{*}{ Number of Sectors } & Before 2010 & After 2010 \\
\cline { 2 - 4 } & Horizontal & 6 & 11 \\
\hline \multirow{2}{*}{ Number of Routes } & Vertical & 11 & 18 \\
\cline { 2 - 4 } & ATS & 67 & 82 \\
\hline \multicolumn{2}{c}{ Number of Waypoints } & 44 & 78 \\
\hline
\end{tabular}

\section{CONCLUSION}

Since air traffic volume of airspace increased in the course of time, the problem of better utilizing airspace capacity was a growing concern. Balancing air traffic demand and airspace capacity is an actual and fundamental research problem for planning and design of airspace. The researchers focused on creating methods and algorithms that increase airspace capacity by redesigning airspace boundaries to reduce or redistribute controller workload and airspace complexity (Zelinski, 2008).

In this study, the airspace structure, the traffic density in the sectors and the potential capacity constraints of Turkish Airspace are analyzed according to 2007 results. A similar study can be performed by using 2013 statistics in order to investigate the performance of new sector structure and the distribution of controller workload in each sector of Turkish airspace. The controller task types should also be considered as well as number of aircraft while calculating of sector densities. In this framework, GIS can also be used for the determination of vertical and horizontal sector boundaries, human resource management and more effective route planning.

Recognition of deficiencies and optimization of assets will ensure maximum capacity through the balancing of operations against available assets. Earlier information of problems in critical areas will allow better co-ordination and management of the provision of en-route capacity and the use of the airspace (ICAO, 2005). In this framework, it is believed that this study will probably be a guide for strategic planning of Turkish Airspace which provides the solutions of existing and predicted problems. 


\section{REFERENCES}

- Albasman, M. and Hu, J. (2010), 'Probability of conflict analysis of 3D aircraft flight based on two-level Markov chain approximation approach', 2010 International Conference on Networking, Sensing and Control (ICNSC), Chicago, USA, pp. 608-613.

- DHMI (2011), 2011 Annual Report, Ankara, Turkey.

- DHMI (2012), Turkish AIP-Aeronautical Information Publication, Aeronautical Publication Service, Ankara.

- Escobar, F., Hunter, G., Bishop, I. and Zerger, A. (2005), Introduction to GIS. Available from http://tmackinnon.com/2005/gis/GISTheory.pdf (accessed on 15/10/2012).

- Eurocontrol (2002), ECAC Airspace Planning Manual, Brussels, Volume 2, Edition 1.0.

- Eurocontrol (2004), Air Traffic Flow \& Capacity Management Strategy, Brussels, Edition 1.2 .

- Eurocontrol (2010), Our International Area of Responsibility. Available from www.eurocontrol.int/muac/public/standardpage/AUintAreaOfRespon.html (accessed on 10/07/2010).

- Eurocontrol (2012), West-to-East Traffic Shift Continues for Summer 2012. Available from www.eurocontrol.int/press-releases/west-east-traffic-shift-continues-summer-2012 (accessed on 10/05/2014)

- Galster, S.M., Duley, J.A., Masalonis, A.J. and Parasuraman, R. (2001), 'Air traffic controller performance and workload under mature free flight: Conflict detection and resolution of aircraft self-separation', The International Journal Of Aviation Psychology, Vol. 11, No. 1, pp. 71-93.

- Hand T., Mao Z. H. and Feron E. (2011), 'Stability of spatially distributed, Intersecting aircraft flows under sequential conflict resolution schemes', 2011 American Control Conference, California.

- Hilburn, B. (2004), Cognitive Complexity in Air Traffic Control: A Literature Review. Available from www.chpr.nl/index_htm_files/CXLIT.pdf (accessed on 10/12/2012).

- ICAO (2005), Global Air Traffic Management Operational Concept, Doc 9854 AN/458, International Civil Aviation Organization, Montreal.

- ICAO (2007), Procedures for Air Navigation Services: Air Traffic Management, Doc 4444 ATM/501, International Civil Aviation Organization, Montreal.

- Kopardekar P., Prevot T. and Jastrzebski M. (2009), 'Traffic complexity measurement under higher levels of automation and higher traffic densities', Air Traffic Control Quarterly, Vol. 17, No. 2, pp. 125-148. 
- Laudeman, I.V., Shelden, S.G., Branstrom, R. and Brasil, C.L. (1998), Dynamic Density: An Air Traffic Management, NASA/TM: 1998-112226.

- Lindberg, L. GV. and Värbrand, P. (2001), Absolute Flow Control: Final Report. Available from

www.eurocontrol.int/eec/gallery/content/public/documents/projects/CARE/linkopingavtech-finalreport.pdf (accessed on 15/12/2012)

- Nguyen-Duc, M., Guessoum, Z., Marin, O., Perrot, J.F., Briot, J.P. and Duong, V. (2008), 'Towards a reliable air traffic control', The Seventh International Conference on Autonomous Agents and Multiagent Systems, Workshop 14: Agents in Traffic and Transportation, Estoril, Portugal, pp. 102-109.

- Nuic, A. (2004), Aircraft Performance Summary Tables for The Base of Aircraft Data (BADA), ECC Note No.12/04, Revision 3.6, Eurocontrol Experimental Center, Brtigny-SurOrge Cedex.

- Salaün, E., Vela, A.E., Feron, E., Clarke, J.P. and Solak, S. (2009), 'A simplified approach to determine airspace complexity maps under automated conflict resolution', 28th Digital Avionics Systems Conference, Orlando, FL, pp. 3.C.5-1 - 3.C.5-13.

- Zelinski, S. (2008), 'Defining critical points for dynamic airspace configuration', 26th International Congress of the Aeronautical Sciences (ICAS), Alaska, USA, pp. 1-12. 